\title{
PERCEPÇÕES DE PROFESSORES DO ENSINO SECUNDÁRIO EM PORTUGAL SOBRE O PAPEL DA DISCIPLINA DE BIOLOGIA E DO GABINETE DE APOIO AOS ALUNOS NA EDUCAÇÃO EM SEXUALIDADE
}

\author{
Cândida Maria Machado GONÇALVES ${ }^{1}$ \\ Teresa VILAÇA ${ }^{2}$
}

RESUMO: A educação em sexualidade (ES) em Portugal, por se tratar de uma área de formação pessoal e social, exige a adopção de um currículo aberto e flexível com a participação ativa dos/as alunos/as. Por essa razão, a ES tem vindo a ser integrada no currículo escolar nomeadamente na disciplina de Biologia e Gabinete de Apoio ao Aluno/a (GAA). Neste sentido, foi desenvolvida uma investigação em escolas portuguesas que, entre outros objetivos, pretendeu: i) caracterizar as concepções de professores/as do GAA e professores/as de Biologia, do Ensino Secundário, sobre o papel da disciplina de Biologia e do GAA na ES dos/as jovens; ii) descrever a forma como concebem o GAA como uma estrutura de suporte na ES. Recorreu-se a uma metodologia qualitativa, exploratória e descritiva, em que a recolha dos dados foi feita através de entrevistas semiestruturadas a professores/as responsáveis pelo GAA $(n=6)$ e professores/asde Biologia $(n=6)$. A maior parte dos/as entrevistados/as atribuiu à Biologia e ao GAA um papel importante na ES no Ensino Secundário, que entenderam como uma área transversal e interdisciplinar onde se ajudam os/as jovens a construir projetos de vida saudáveis. $\mathrm{Na}$ sua perspetiva, o programa de Biologia permite o conhecimento da dimensão biológica da sexualidade, daí a importância da sua articulação com o GAA. O GAA foi considerado como uma estrutura de suporte à ES, porque além de colaborar nos projetos de ES deverá ser um serviço social, onde o/a professor/a age como conselheiro/a e encaminha o/a aluno/a para outras instituições.Estes resultados têm implicações a nível da formação de professores/as, da articulação entre as áreas curriculares disciplinares e o GAA e da (re) estruturação dos GAA em função dos normativos legais.

PALAVRAS-CHAVE: Educação em sexualidade. Disciplina de Biologia. Gabinete de Apoio ao aluno/a. Professores/as. Portugal.

\section{Enquadramento Teórico}

\section{Analisando os Princípios Orientadores da Revisão Curricular do Ensino}

Secundário Português e os planos de estudo do Curso Científico-Humanístico de Ciências e Tecnologias do currículo nacional, torna-se evidente que a área curricular de Biologia do $12^{\circ}$ ano de escolaridade se assume, por excelência, como a disciplina que

\footnotetext{
${ }^{1}$ Escola EB2,3 Carlos Teixeira. Fafe - PO - Portugal.4820-118 - candida.goncalves@gmail.com

${ }^{2}$ UMinho - Universidade do Minho. Braga - PO - Portugal.4710-057 - tvilaca@ie.uminho.pt
} 
permite o desenvolvimento sistemático da dimensão biológica da sexualidade, respeitando a liberdade de desenvolver opções éticas, socioeconómicas e políticas (LISBOA, 2003, 2004).

De facto, o programa de Biologia de $12^{\circ}$ ano de escolaridade tem como finalidades principais (LISBOA, 2004, p.4):

1) a construção e aprofundamento de conhecimentos de Biologia úteis para o desenvolvimento de competências que permitam o exercício da cidadania responsável, a aprendizagem ao longo da vida e a decisão sobre o prosseguimento de estudos relacionados com esta área do saber.

2) O reconhecimento da relevância da Biologia e da Biotecnologia nos dias de hoje, uma vez que influenciam a qualidade de vida das pessoas e a organização das sociedades, ao apresentarem alternativas e originarem questões que exigem tomadas de decisões a nível tecno-científico, político, social e ético.

Estas duas finalidades mostram como a disciplina de Biologia de $12^{\circ}$ ano, ramo da ciência que estuda a vida, é importante para educar sexualmente o indivíduo. Por um lado, porque é através dela que o indivíduo compreende o funcionamento do seu corpo, percebendo o porquê das suas reações, podendo assim controlá-las de uma forma consciente e responsável. Por outro lado, percebe que os avanços da biotecnologia têm permitido uma maior qualidade de vida sexual, como por exemplo, o controlo da reprodução através dos métodos contracetivos e a possibilidade de identificação de doenças genéticas, através da análise do líquido amniótico, entre outras possibilidades.

Desta forma, o ensino de Biologia de $12^{\circ}$ ano é importante para o conhecimento biofisiológico e para o desenvolvimento pessoal e social do/a aluno/a, contribuindo para que os/as cidadãos/ãs interajam de forma autónoma, consciente e construtiva com a sociedade e o ambiente, permitindo ajudar os/as alunos/as a desenvolver formas de relacionamento responsáveis com os/as seus/suas concidadãos/dãs e também com os outros seres vivos. Isto acontece porque um dos grandes objetivos da educação em sexualidade é o de contribuir para uma vivência mais informada, mais gratificante, mais autónoma e mais responsável da sexualidade.

Consistentemente com aquelas finalidades, o Programa da disciplina de Biologia de $12^{\circ}$ ano (LISBOA, 2004) preconiza a reprodução não só centrada no ser humano mas nos seres vivos assexuados e sexuados de uma forma geral. Este nível de 
concetualização tem a grande vantagem de permitir compreender o homem e a mulher e o seu processo reprodutivo em continuidade com os outros seres vivos.

No programa de Biologia do $12^{\circ}$ ano, a ênfase é colocada na reprodução sexuada, de uma maneira geral, e na reprodução humana, de uma maneira particular. Também é realçado o papel fundamental da evolução científica e tecnológica associado à regulação da fertilidade e à engenharia genética. Neste programa pode ler-se (LISBOA, 2004, p.5):

O que pode ser feito ao nível dos processos reprodutivos? Que desafios se colocam à genética? E ao controlo de doenças? Procedendo-se ao desenvolvimento de conteúdos concetuais como: (a) reprodução humana; (b) gametogénese e fecundação (c) controlo hormonal; (d) desenvolvimento embrionário e gestação; (e) Manipulação da fertilidade; (f) Património genético; (g) Transmissão de caraterísticas hereditárias; (h) organização e regulação do material genético; (i) Alterações do material genético; (1) mutações; e (m) fundamentos de engenharia genética.

Estas questões e conteúdos conceituais vão de encontro aos objetivos da educação em sexualidade em meio escolar para o Ensino Secundário, ao nível da consolidação dos conhecimentos, como se pode ler no excerto seguinte desse documento:

[...] dimensões anátomo-fisiológica, psicoafetiva e sociocultural da expressão da sexualidade; do corpo sexuado e dos seus órgãos internos e externos; dos mecanismos de reprodução; do planeamento familiar e em particular, dos métodos contracetivos; das doenças de transmissão sexual, formas de prevenção e tratamento; dos mecanismos da resposta sexual humana; dos recursos existentes para a resolução de situações relacionadas com a saúde sexual e reprodutiva (LISBOA, 2000, p.91).

A abordagem destes conteúdos é, de facto, importante para o desenvolvimento da sexualidade do/a aluno/a, mas é o/a professor/a que determinará se a área curricular disciplinar de Biologia será uma mera abordagem do conhecimento conceitual, com o caráter fragmentado do ensino e estanque dos saberes, ou permitirá a reflexão sobre um conjunto de valores e atitudes face à sexualidade humana, com uma perspetiva integradora do saber fundamental, quer para a formação global do/a aluno/a quer para os seus percursos futuros, utilizando para isso metodologias participativas e ativas. 
As áreas curriculares não disciplinares, nomeadamente a Área de Projeto (AP) surgem como outro espaço em que tem lugar o desenvolvimento da temática da sexualidade mas, desta vez, de uma forma interdisciplinar e transversal. De acordo com as orientações de Área de Projeto dos Cursos Científicos Humanísticos do Ministério da Educação, homologadas em Agosto de 2006, a AP visa a realização de projetos, com a finalidade de promover o desenvolvimento pessoal e social nos/as alunos/as e nos/as professores/as através do trabalho cooperativo, fundamentado na exploração e aplicação de processos mentais complexos, promotores da confiança em si e nos outros, do gosto pela investigação e geradores de autonomia intelectual e cívica (LISBOA, 2006).

A AP é também um espaço curricular propício ao desenvolvimento de uma aproximação da escola à comunidade e à sociedade em que se insere, potenciada pelo trabalho desenvolvido pelos/as alunos/as e professores/as. Sem conteúdos definidos e planeada com base na metodologia do trabalho de projeto, a AP dá oportunidade aos jovens de conhecerem e refletirem sobre problemas sociais, económicos, tecnológicos, científicos, artísticos, ambientais e culturais, de uma forma integrada (LISBOA, 2006).

Assim, a AP pode, inequivocamente, contribuir de forma positiva para a formação pessoal e social dos/as jovens, através de uma educação para a cidadania, que deve ser vivida, partilhada e refletida em contextos reais e diversificados, tal como é referido nas Linhas Orientadoras da Educação Sexual em Meio Escolar (LISBOA, 2000) em termos de competências a desenvolver em educação em sexualidade no Ensino Secundário. Sendo assim, e entre as Orientações de Área de Projeto, aquelas que mais diretamente se relacionam com a educação em sexualidade são as seguintes:

1. promover uma cultura de liberdade, participação, reflexão, qualidade e avaliação que realce a responsabilidade de cada um nos processos de mudança pessoal e social;

2. [...]

3. desenvolver atitudes de responsabilização pessoal e social dos alunos na constituição dos seus itinerários e projetos de vida, sob uma perspetiva de formação para a cidadania participada, para a aprendizagem ao longo da vida e para a promoção de um espírito empreendedor. (LISBOA, 2006, p.8) 
Nesta ótica, a AP surge como um espaço apropriado para a abordagem da sexualidade humana, como é sublinhado nas Linhas Orientadoras da Educação Sexual em Meio Escolar (LISBOA, 2000), isto é, através da integração curricular de forma transversal e interdisciplinar, já que a maioria das áreas curriculares apresentam pontos de correspondência, paralelismo ou complementaridade com os objetivos da educação em sexualidade.

No Ensino Secundário, só existe AP no $12^{\circ}$ ano de escolaridade, sendo recomendado pelo Grupo de Trabalho em Educação Sexual, no seu relatório de final de 2007, a utilização desta área curricular não disciplinar para a dinamização de projeto de educação para a saúde, nomeadamente sexualidade.No nosso entender, a AP não deveria ter um caráter terminal, pois seria muito mais proveitoso que tal processo fosse desencadeado ao longo do Ensino Secundário, como é feito no Ensino Básico, uma vez que os alunos do Ensino Secundário estão num novo estádio de desenvolvimento, a nível psicossocial e num processo de autonomia e construção de identidade adulta, processo esse que apresenta grande variação individual, podendo coexistir jovens na mesma fase etária em diferentes graus de desenvolvimento, o que dificulta a possibilidade de, num só ano, serem atingidas todas as finalidades da AP.

A Lei $n^{\circ} 120 / 99$ de 11 de Agosto (PORTUGAL, 1999), que reforça as garantias do direito à saúde reprodutiva, aborda, entre outros assuntos, a promoção da saúde sexual no contexto escolar, designadamente nos Gabinetes de Apoio a Alunos/as (GAA). A Lei define que no ensino Básico e Secundário será implementado um programa para a promoção da saúde e da sexualidade humana, proporcionando informações/conteúdos adequados nas diversas vertentes desta matéria: fisiológica, psicológica e social. Estes conteúdos serão incluídos harmoniosamente nas áreas curriculares disciplinares e não disciplinares, como anteriormente referido, e em GAA, no sentido de promover uma atitude individual e responsável, adequada aos diferentes níveis etários.O Artigo $3^{\circ}$ contempla as "Doenças Sexualmente Transmissíveis", mencionando a criação de um "Gabinete de Apoio aos/às Alunos/as" e "o acesso a preservativos através de meios mecânicos, em todos os estabelecimentos do ensino superior e nos estabelecimentos do ensino secundário, por decisão dos órgãos diretivos, ouvidas as respectivas associações de pais e alunos".

Segundo o Grupo de Trabalho de Educação Sexual [GTES] (2005), compete ao/à professor/a responsável pelo GAA: atuar como adulto/a de referência, com capacidade de ouvir o que o/a aluno/a tem para dizer; orientar e realizar tarefas de 
despiste, de problemas graves; ser supervisionado/a regularmente por um/a psicólogo/a clínico/a com experiência na área da sexualidade, ou articular as suas ações com o Serviço de Psicologia e Orientação. Sendo assim, é necessária uma cumplicidade muito estreita entre o/a professor/a responsável pelo GAA e as estruturas de saúde na comunidade.

Prevê-se para o GAA a permanência de um/a professor/a da escola ou do agrupamento de escolas em regime de rotatividade. No caso da escola dispor de Psicólogo/a e/ou Assistente Social, deve haver uma estreita colaboração com o GAA. O Relatório Final do Grupo de Trabalho de Educação Sexual (GRUPO DE TRABALHO DE EDUCAÇÃO SEXUAL, 2007b), publicado em Setembro de 2007, propunha ainda a solicitação da colaboração do Instituto de Apoio à Juventude, dada a experiência que tem de contato com os/as jovens e também pelos materiais de apoio que possam vir a ser fornecidos.

Os GAA não devem substituir os gabinetes de apoio técnico, do tipo aconselhamento médico-psicológico, que poderão ser ativados através de recursos humanos da escola, ou dinamização de parcerias com os Centros de Saúde, Autarquias ou Centros de Jovens (GRUPO DE TRABALHO DE EDUCAÇÃO SEXUAL, 2005), para tornar possível o encaminhamento imediato de casos problemáticos que não possam ser tratados pelo/a responsável do GAA. Ainda segundo o Grupo de Trabalho de Educação Sexual (2005), apesar da extrema importância dos GAA em todas as escolas, estes assumem uma relevância maior nas escolas de Ensino Secundário. Os GAA aparecem nestes níveis de escolaridade praticamente como a única forma de apoio e assumem especial importância por ser nesta faixa etária que surgem muitos/as adolescentes a consumirem tabaco, haxixe, álcool e outras drogas e a terem relações sexuais desprotegidas. Tais situações de risco, para além da percepção de mal-estar, justificam por si a urgência de implementar GAA polivalentes, amplamente disponíveis e sem burocracias.

Para que os GAA sejam viáveis, é necessária a atribuição de horas não letivas aos/às professores/as no espaço escolar, para que possam assegurar um serviço de atendimento genérico e regular (GRUPO DE TRABALHO DE EDUCAÇÃO SEXUAL, 2007b). Além disso, é essencial: a confidencialidade por parte dos/as responsáveis pelos GAA; a colaboração dos/as alunos/as na definição dos objectivos dos gabinetes e na dinamização e divulgação desses espaços e o estabelecimento de parcerias com os Centros de Saúde, Hospitais e Maternidades locais. Em relação aos 
temas a abordar, o GTES sugere: género, família, paternidade, interação no namoro, respeito/violência, assertividade, comportamentos sexuais veiculados pela internet, abusos sexuais e maus tratos e projeto de vida (GRUPO DE TRABALHO DE EDUCAÇÃO SEXUAL, 2007b). É recomendado que a abordagem desses assuntos não seja excessivamente preventiva, abstrata e sanitária, desligada da realidade e da reflexão sobre valores, atitudes, sentimentos, e comportamentos sexuais dos adolescentes, implicando necessariamente uma articulação entre responsáveis do GAA e professores de Biologia, trabalhando, assim, de uma forma sincronizada.

Neste sentido, foi desenvolvida uma investigação em escolas portuguesas que, entre outros objetivos, pretendeu: i) caracterizar as perceções de professores do GAA e professores de Biologia, do Ensino Secundário, sobre o papel da disciplina de Biologia e do GAA na ES dos jovens; ii) descrever a forma como concebem o GAA como uma estrutura de suporte na ES.

\section{Metodologia}

\section{Amostra}

Como os GAA são estruturas que funcionam em apenas algumas escolas com Ensino Secundário, foram selecionadas seis escolas com Ensino Secundário e com GAA e dentro de cada um destes seis estabelecimentos de ensino, foi selecionado o/a responsável pelo GAA (n=6) e o/a professor/a de Biologia $(n=6)$.

Todas as entrevistadas eram mulheres. A idade das professoras variou entre 41 a 48 anos e o número de anos de serviço entre 18 e 25 anos. Todasas professoras, com exceção de uma professora (PGAA6), referiram ter formação em Educação em Sexualidade e nenhuma professora se encontrava a lecionar a área curricular não disciplinar de Área de Projeto. A maioria das professoras possuía licenciatura em Biologia e Geologia (via ensino) e formação especializada, com exceção das professoras PGAA4, PGAA5 e PGAA6, que eram licenciados respectivamente em Direito, Português/Francês e Filosofia. As professoras PB4 e PGAA5 não possuíam formação especializada.

\section{Instrumento de Recolha de Dados}

Neste estudo foram validados dois guiões de entrevista aplicados, respetivamente, a professoras de Biologia de $12^{\circ}$ ano do Ensino Secundário $(\mathrm{PB}) \mathrm{e}$ professoras responsáveis pelo Gabinete de Apoio aos/às Alunos/as (PGAA). O guião 
das entrevistas estava organizado em cinco dimensões: i) caracterização da amostra (PGAA, PB); ii) perceções sobre o papel da Biologia e do Gabinete de Apoio aos/às Alunos/as na educação em sexualidade (PGAA, PB); (III) práticas de educação em sexualidade nas aulas de Biologia do $12^{\circ}$ ano e em articulação com o GAA (PB)/ (III) caracterização do GAA nas escolas em estudo (PGAA) e (IV) práticas da educação em sexualidade no GAA em articulação com a Biologia de $12^{\circ}$ ano (PGAA).

\section{Apresentação dos Resultados}

\section{Relevância da Biologia do Ensino Secundário e do GAA para a Educação em Sexualidade dos Jovens}

A importância do papel da Biologia do ensino Secundário na educação em sexualidade dos/as alunos/as é preponderante no que diz respeito ao fornecimento de informação relativa à morfologia e fisiologia do sistema reprodutor, assim como em relação às formas de prevenção de comportamentos sexuais de risco (gravidez precoce indesejada e contágio de IST's) (Tabela 1).

Tabela 1 - Papel da Biologia do Ensino Secundário na Educação em Sexualidade

$(\mathrm{N}=12)$

\begin{tabular}{|c|c|c|c|c|c|c|c|c|c|c|c|}
\hline & \multicolumn{6}{|c|}{ Prof. Bio. $(n=6)$} & \multicolumn{4}{|c|}{ Prof. GAA $(n=6)$} & \multirow[b]{2}{*}{ Total } \\
\hline & 1 & 2 & 3 & 4 & 5 & $6 !$ & 12 & 3 & 45 & $6 i$ & \\
\hline $\begin{array}{l}\text { Desenvolvimento de conteúdos } \\
\text { biofisiológicos da sexualidade e } \\
\text { saúde sexual }\end{array}$ & $\sqrt{ }$ & $\sqrt{ }$ & $\sqrt{ }$ & $\sqrt{ }$ & 1 & $\sqrt{ } \sqrt{\vdots}$ & $\sqrt{ }$ & $\sqrt{ }$ & $\sqrt{ } \sqrt{ }$ & $\sqrt{!}$ & 12 \\
\hline $\begin{array}{l}\text { Desenvolvimento de competências } \\
\text { pessoais e sociais, na perspetiva } \\
\text { de resolução de problemas }\end{array}$ & & $\sqrt{ }$ & & $\sqrt{ }$ & & 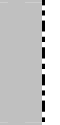 & & $\sqrt{ }$ & $\sqrt{ }$ & 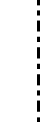 & 4 \\
\hline $\begin{array}{l}\text { Desenvolvimento de competências a } \\
\text { nível das atitudes, valores e } \\
\text { comportamentos afetivo-sexuais }\end{array}$ & & & & $\sqrt{ }$ & & $\vdots$ & & $\sqrt{ }$ & $\sqrt{ }$ & $\vdots$ & 3 \\
\hline
\end{tabular}

Fonte: elaboração própria.

Para uma professora (PB1), as razões apontadas para o papel da Biologia na educação em sexualidade prenderam-se com o facto das turmas serem muito heterogéneas e nem todos/as os/as alunos/as estarem no mesmo estádio de desenvolvimento, daí a Biologia deveria desenvolver os temas relacionados com a parte científica e obrigatória e não deveria fugir disso para não ferir susceptibilidades. Para outras entrevistadas, a informação biológica é extremamente importante para a aquisição de competências de tomada de decisão no percurso sexual do/a jovem, porque sem esses conhecimentos básicos o/a aluno/a não poderá evoluir para estádios de 
desenvolvimento de competências pessoais e sociais decisivos na elaboração do seu percurso de vida (PB2, PB3, PB4, PB5, PG1, PG4, PG5). Outra razão apontada é a necessidade preventiva, dado as informações dadas ainda serem imprescindíveis para a formação da saúde sexual dos/as alunos/as (PG2, PG3, PG6).

No que concerne aos desafios e barreiras que os/as professores/as de Biologia enfrentam na implementação da educação em sexualidade, as respostas dadas pelas entrevistadas centraram-se nos/as professores/as (tabela 2).

Tabela 2 - Desafios e barreiras que o/a professor/a de Biologia do Ensino Secundário pode enfrentar na Educação em Sexualidade

$(n=6)$

\begin{tabular}{|c|c|c|c|c|c|c|c|}
\hline & \multicolumn{6}{|c|}{ Prof. Bio. $(n=6)$} & \multirow[b]{2}{*}{ Total } \\
\hline & 1 & 2 & 3 & 4 & 5 & 6 & \\
\hline \multicolumn{8}{|l|}{ Desafios } \\
\hline $\begin{array}{l}\text { Envolver todos os professores na contribuição a dar na formação sexual } \\
\text { dos alunos }\end{array}$ & 1 & 1 & & & & & 2 \\
\hline $\begin{array}{l}\text { Estabelecer um elo de comunicação professor-aluno, em que estes } \\
\text { encontrem no professor um verdadeiro amigo e confidente. }\end{array}$ & & & 1 & & 1 & & 2 \\
\hline Contribuir para a construção de projeto de vida saudável dos jovens & & & & 1 & & 1 & 2 \\
\hline \multicolumn{8}{|l|}{ Barreiras } \\
\hline $\begin{array}{l}\text { Fazer Educação em Sexualidade, tendo em conta a heterogeneidade dos } \\
\text { alunos da turma a todos os níveis (grau de desenvolvimento, cultura, } \\
\text { religião...) }\end{array}$ & 1 & & & & & 1 & 2 \\
\hline Possuir perfil para fazer Educação em Sexualidade & & 1 & 1 & & & & 2 \\
\hline $\begin{array}{l}\text { Desfazer de mitos que persistem ao longo das gerações e que são } \\
\text { prejudiciais à vida sexual dos jovens }\end{array}$ & & & & 1 & 1 & & 2 \\
\hline
\end{tabular}

Fonte: elaboração própria.

Um dos desafios na implementação da educação em sexualidade foi, segundo duas das professoras de Biologia (dois em seis), conseguir que, de facto, a educação em sexualidade seja feita de uma forma transversal e interdisciplinar. Para tal é necessário que todos/as os/as outros/as professores/as descartem a ideia de que é o/a professor/a de Biologia aquele que tem mais aptidões para fazê-la, compreendendo que só com a contribuição de todos/as é possível desenvolver os diversos conhecimentos e áreas do saber da formação sexual integral dos/as jovens.

Outro desafio apresentado (dois em seis) foi o/a professor/a conseguir ser um/a melhor amigo/a adulto/a do/a aluno/a, pois só assim será possível que eles/as se aproximem do/a professor/a e dialoguem sobre os problemas que os/as atormentam, permitindo-lhes solucionar ou encaminhar-se para a solução dos problemas e, consequentemente, o/a professor/a contribui desta forma para a construção do projeto de vida dos/as jovens. 
Em relação às barreiras encontradas pelos/as professores/as de Biologia na implementação da educação em sexualidade no Ensino Secundário, destacou-se à partida, o facto de a maioria dos/as professores/as, incluindo os/as de Biologia, não possuírem perfil para realizarem a educação em sexualidade (dois em seis).

Outra barreira também muito difícil de transpor, segundo as entrevistadas, foi a de saber até que ponto o/a professor/a deve desenvolver os temas, ou introduzir novo tema, dado a turma ser um conjunto de indivíduos, com diferentes necessidades e com direito ao respeito pelas sua cultura e religião: “[...] se é bem verdade que os jovens têm direito a possuir conhecimentos relativos à educação sexual, também é verdade que outros terão direito a manter a sua inocência." (PB4).

E, finalmente, a terceira barreira referida pelas professoras (dois em seis), foi desfazer mitos sexuais que persistem ao longo das gerações, desconstruindo conceções alternativas que são, algumas delas, extremamente prejudiciais e que levam a comportamentos sexuais de risco e às consequências inerentes a estes comportamentos. Uma professora de Biologia do Ensino Secundário falou de um mito que disse ser frequente nos alunos: “[...] se tiver relações sexuais em pé, não correm o risco de engravidar" (PB4).

A maioria das entrevistadas afirmou ser importante a existência do GAA no Ensino Secundário: todas as professoras do GAA, e três professoras de Biologia de $12^{\circ}$ ano (Tabela 3).

Tabela 3 - Importância do GAA na Educação em Sexualidade dos/as alunos/as do Ensino Secundário

$(\mathrm{N}=12)$

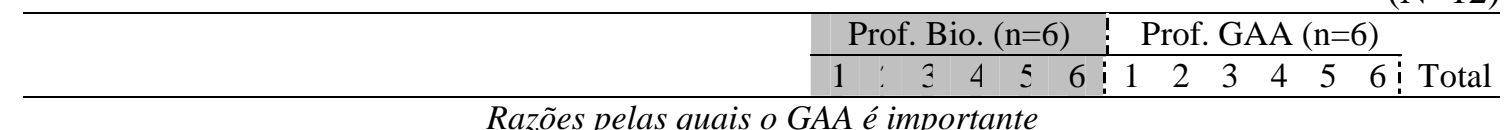

Razões pelas quais o GAA é importante
Por ser um espaço de sigilo, de atendimento
individualizado, a que os/as alunos/as podem
recorrer para arranjar alternativas na resolução de
problemas de índole sexual


Fonte: elaboração própria.

A primazia das razões apresentadas (sete em doze entrevistadas), tem a ver com a possibilidade da existência de um espaço de confidencialidade em que o aconselhamento individualizado pode, eventualmente, dar resposta a problemas que sejam decisivos no percurso de vida do/a jovem, prestando o apoio que a família não consegue dar, na sociedade em que vivemos.

Em relação à posição assumida por alguns elementos da amostra em estudo, entre as razões que as levou a responderem que o GAA não é importante na educação em sexualidade no ensino Secundário, a principal $(n=2)$, prendeu-se com o facto de os/as alunos/as não se quererem expor visitando o GAA. Foram apresentadas várias justificações para esta opinião, entre elas, o facto de terem medo: de serem marginalizado pelos/as colegas (PB2) e de falarem com um desconhecido sobre assuntos íntimos (PB3).

O grande desafio das professores responsáveis pelo GAA, independentemente do tempo de existência deste e da especificidade de cada um, foi encontrar a forma de conseguir conquistar a confiança da população juvenil e, com isso, dinamizar uma maior participação no atendimento individualizado e acompanhamento na área da sexualidade, função ainda muito subaproveitada em todos os GAA do referido estudo: “(Suspiro) É encontrar um caminho que resulte!!!” (PG1) (Tabela 4).

Tabela 4 - Desafios e barreiras que o professor do GAA pode enfrentar na Educação Sexual

$(n=6)$

\begin{tabular}{|c|c|c|c|c|c|c|}
\hline & \multicolumn{5}{|c|}{ Prof. GAA $(n=6)$} & \multirow[b]{2}{*}{ Total } \\
\hline & 12 & 3 & 4 & 5 & $\epsilon$ & \\
\hline Desafios & & & & & & \\
\hline $\begin{array}{l}\text { Estabelecer um elo de comunicação entre o/a professor/a do GAA e o/a aluno/a, } \\
\text { desencadeando a confiança e com isso a procura do GAA como um espaço } \\
\text { de efetivo apoio de ajuda aos/às jovens. }\end{array}$ & 1 & 1 & 1 & 1 & 1 & 6 \\
\hline $\begin{array}{l}\text { Que a comunidade escolar perceba a importância do GAA na vida dos/as } \\
\text { jovens }\end{array}$ & & & 1 & & & 1 \\
\hline Contribuir para a construção de projeto de vida saudável dos/as jovens & & & & & 1 & 1 \\
\hline Barreiras & & & & & & \\
\hline A falta de tempo e à vontade para os/as alunos/as irem ao GAA & 1 & & & & & 2 \\
\hline Falta de espaço condigno para o atendimento individualizado do/a jovem & 1 & & 1 & 1 & & 3 \\
\hline $\begin{array}{l}\text { A falta de disponibilidade horária da equipa de intervenção no GAA, } \\
\text { impossibilitando a abertura permanente do GAA durante o horário escolar }\end{array}$ & 1 & 1 & & 1 & & 3 \\
\hline A burocracia obrigatória para a implementação do projeto GAA & & 1 & & & & 1 \\
\hline A falta de recursos económicos & & 1 & 1 & & & 2 \\
\hline Dificuldade em arranjar e articular parcerias & & 1 & & & 1 & 2 \\
\hline
\end{tabular}

Fonte: elaboração própria. 
As barreiras estão relacionadas com as infraestruturas do GAA, com a logística, recurso humanos e materiais e disponibilidade horária do GAA que se tornam um entrave para o pleno funcionamento dos mesmos.

\section{O GAA como Estrutura de Suporte na Educação em Sexualidade}

Constata-se que tendo em conta o total da amostra, as condições físicas do gabinete foram consideradas muito importantes, assim como os recursos didáticos e técnicos das diferentes especialidades que o devem compor (Tabela 5).

Tabela 5 - Como deve ser oGAA para apoiar a Educação em Sexualidade de alunos/as do Ensino Secundário

$(\mathrm{N}=12)$

\begin{tabular}{|c|c|c|c|c|c|c|c|c|c|c|c|c|c|c|}
\hline & \multicolumn{6}{|c|}{ Prof. Bio. $(n=6)$} & \multicolumn{7}{|c|}{ Prof. GAA $(n=6)$} & \multirow[b]{2}{*}{ Total } \\
\hline & 1 & 2 & 3 & 4 & 5 & 6 & 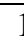 & 2 & 3 & & & 5 & 6 & \\
\hline Equipa multidisciplinar de saúde e de educação & 1 & & 1 & 1 & & $\sqrt{ }$ & 1 & & & & & $\sqrt{ }$ & $\sqrt{i}$ & 7 \\
\hline Possuir professores/as de ambos os sexos & & & & & & & & & & & & & & 1 \\
\hline Ter profissionais estranhos/asà escola & 1 & & & & & & & & & & & & & 1 \\
\hline $\begin{array}{l}\text { Num local de fácil acesso, espaço acolhedor, discreto } \\
\text { privado e com recursos didáticos auxiliares da } \\
\text { Educação em Sexualidade dos/as jovens }\end{array}$ & 1 & & & & & & & & $\sqrt{ }$ & & & $\sqrt{ }$ & $\sqrt{ } !$ & 4 \\
\hline Gabinete aberto a toda comunidade escolar & & & & & & $\sqrt{ }$ & & & & & & & & 1 \\
\hline $\begin{array}{l}\text { Gabinete que funcione como espaço de formação geral } \\
\text { aos/às mais jovens (espaço lúdico e de convívio } \\
\text { dos/as alunos/as) }\end{array}$ & & 1 & 1 & & 1 & & & & & & & & & 3 \\
\hline $\begin{array}{l}\text { Gabinete de apoio confidencial e aconselhamento } \\
\text { individualizado }\end{array}$ & & & & & & & & $\sqrt{ }$ & & & & & & 2 \\
\hline Envolver os/as alunos/as no funcionamento do GAA & & & & 1 & & & & & & & & & & 1 \\
\hline
\end{tabular}

Fonte: elaboração própria.

O GAA deve possuir um espaço próprio que seja de fácil acesso aos/às alunos/as e ao mesmo tempo também discreto e confidencial, no sentido de manter o anonimato da frequência dos/as alunos/as ao gabinete, e possuir efetivas condições de trabalho, necessidade sentida tanto pelos/as técnicos/as como pela comunidade participante.O excerto da entrevista seguinte de uma responsável por um GAA ilustra esta opinião:

[...] os gabinetes de apoio aos alunos tenham a dignidade que merecem, ou seja, tem que funcionar de um modo autónomo e independente, em vez de ser sempre um espaço emprestado, ou se estão livres, ser um espaço com toda a dignidade que precisa aquele espaço, ou seja, tal como a biblioteca tem o seu espaço próprio, o GAA também deveria ter, porque a população que recorre a esse espaço merece toda a dignidade a nível do atendimento e depois os 
técnicos, precisam de sentir que efetivamente têm condições para trabalhar, isso é fundamental. (PG6)

Outra condição importante para o bom funcionamento do gabinete no apoio prestado à sexualidade dos/as alunos/as no Ensino Secundário foi a existência de uma equipa multidisciplinar da área da saúde e da educação (enfermeiro/a, médico/a, nutricionista, psicólogo/a, serviço social, professores/as) que façam parte do elenco da escola e que tenham tempo e disponibilidade para o atendimento aos/às jovens, condições inexistentes em todos os GAA em estudo, evitando que os/as alunos/as estejam longo tempo à espera de um atendimento e que, dentro do possível, a escola tenha condições para resolver os problemas existentes, sem estar à espera da boa vontade de outrem:

[...] para resolver um espectro amplo de problemáticas que envolve o aluno, permitindo que este avance para a sua realização pessoal [...] para atingir os objectivos do GAA é necessária uma equipa multidisciplinar permanente na escola. Porque ainda dependemos da boa vontade, e é muito difícil reunir vontades, e a vida da "pessoa", não pode depender de boas vontades! (PG6)

Através da análise dos resultados, tornou-se claro que o principal objetivo do GAA para as entrevistadas foi ajudar os/as adolescentes a gerir conflitos internos, de forma a tentar ajudar na resolução de problemas vivenciados pelos/as jovens e orientá-los/as, procurando minimizar os problemas através do apoio na escola ou, caso seja necessário, encaminhá-los/as para instituições que possam ajudar a superálos (Tabela 6).

Tabela 6 - Objetivos principais desejáveis para o GAA

\begin{tabular}{|c|c|c|c|c|c|c|c|c|c|c|c|c|}
\hline & \multicolumn{6}{|c|}{ Prof. Bio. $(n=6)$} & \multicolumn{6}{|c|}{ Prof. GAA $(n=6)$} \\
\hline & 1 & 2 & 3 & 4 & 5 & 6 & 12 & 3 & 4 & 5 & 6 & Total \\
\hline $\begin{array}{l}\text { Dinamizar atividades para a comunidade escolar na } \\
\text { tentativa de esclarecer dúvidas/ problemas } \\
\text { diagnosticadas no projeto }\end{array}$ & & & 1 & 1 & & & & $\sqrt{ }$ & & & & 3 \\
\hline Ajudar na elaboração do seu projeto de vida & & & & & & v & & & & & & 3 \\
\hline $\begin{array}{l}\text { Ajudar a gerir os seus conflitos internos enquanto } \\
\text { adolescentes de forma a evitar comportamentos de } \\
\text { risco }\end{array}$ & 1 & 1 & & & 1 & & $\sqrt{ }$ & & & $\sqrt{ }$ & $\sqrt{ }$ & 7 \\
\hline
\end{tabular}

Fonte: elaboração própria.

A professora do GAA clarificou esta visão no extrato da entrevista que a seguir se apresenta: 
Tentar responder ao máximo de problemáticas existentes na população escolar. O responder não significa solucionar, pode significar encaminhar, portanto uma estrutura que acolha, que perceba qual é o problema e que encontre o melhor caminho para a resolução. Esse caminho pode ser dentro da escola, ou fora da escola [...] E encaminhar para... e depois manter a retaguarda, de modo a que o aluno não veja o seu percurso de vida interrompido. Se estamos na escola a função é afastar todos os obstáculos que possam impedir o percurso escolar do aluno, esta é a nossa vocação! (PG6)

A maioria das entrevistadas, entendeu que o GAA deve apoiar o/a aluno/a nas múltiplas problemáticas em que a sua vida está envolvida, e não exclusivamente a nível sexual. Também defenderam que o GAA não deve limitar-se a abarcar apenas os/as alunos/as do Ensino Secundário, mas também do Ensino Básico.

Para a maioria das entrevistadas $(n=7)$, o GAA deve funcionar para ajudar a gerir os conflitos internos dos/as adolescentes de forma a evitar comportamentos de risco, deverá privilegiar um horário bastante lato, aberto nos intervalos, à hora do almoço, depois do expediente escolar e se possível à noite (Tabela 7).

Tabela 7 - Como deve funcionar o GAA

$(\mathrm{N}=12)$

\begin{tabular}{|c|c|c|c|c|c|c|c|c|c|c|c|c|c|}
\hline & \multicolumn{6}{|c|}{ Prof. Bio. $(n=6)$} & \multicolumn{6}{|c|}{ Prof. GAA $(n=6)$} & \multirow[b]{2}{*}{ Total } \\
\hline & 1 & 2 & 3 & 4 & 5 & 6 & 1 & 2 & 3 & 4 & 5 & 6 & \\
\hline Atendimento individualizado & & & & & & & & & & & & $\sqrt{ }$ & 1 \\
\hline Sigilo absoluto & 1 & 1 & & & & & & $\sqrt{ }$ & $\sqrt{ }$ & & & & 4 \\
\hline $\begin{array}{l}\text { Horário abrangente e flexível tendo em conta as } \\
\text { necessidades da comunidade }\end{array}$ & 1 & 1 & & 1 & & v & & $\sqrt{ }$ & $\sqrt{ }$ & & $\sqrt{ }$ & & 7 \\
\hline $\begin{array}{l}\text { Plano de intervenção de acordo com as necessidades } \\
\text { diagnosticadas nos alunos }\end{array}$ & & & & & & & & & $\sqrt{ }$ & & & & 1 \\
\hline Acesso online & & 1 & & & & & & & & & & & 1 \\
\hline Estar coordenado com os restantes projetos de EpS & & & & & 1 & & & & & & & & 1 \\
\hline $\begin{array}{l}\text { Total disponibilidade dos adultos para ajudar os } \\
\text { jovens }\end{array}$ & & & 1 & & & & & & & & & & 1 \\
\hline $\begin{array}{l}\text { Equipa multidisciplinar que realize um trabalho } \\
\text { cooperativo }\end{array}$ & & & & & & $\sqrt{ }$ & & & $\sqrt{ }$ & $\sqrt{ }$ & & & 3 \\
\hline Avaliação constante do GAA & & & & & & v & $\sqrt{ }$ & & $\sqrt{ }$ & & & & 3 \\
\hline Integração dos alunos no GAA & & & & & & v & & & & & & & 1 \\
\hline Autonomia na gestão do GAA & & & & & & & & & & & $\sqrt{ }$ & & 1 \\
\hline Rotatividade horária dos profissionais no GAA & & & & 1 & & & & & & & & & 1 \\
\hline
\end{tabular}

Fonte: elaboração própria.

Foram apresentadas como razões para este funcionamento, a falta de tempo disponível dos/as jovens e a necessidade de manter o anonimato, daí o horário fora do período de aulas ou mesmo no fim-de-semana. 
Outras condições de funcionamentotambém consideradas importantes foram o sigilo absoluto $(n=4)$ e o atendimento individualizado $(n=1)$, feito por uma equipa multidisciplinar $(n=3)$ que trabalhe de forma cooperativa e não de forma individual, como se de consultas avulsas se tratasse, sem esquecer a avaliação constante do projeto $(\mathrm{n}=3)$, e arranjar alternativas positivas para ajustar-se à comunidade escolar em que o GAA está inserido:

[...] com uma equipa multidisciplinar que faça parte da escola, com horários fixos, embora flexíveis de acordo com as necessidades da comunidade. A equipa deve trabalhar na base da partilha e não em termos de atividades estanques, por exemplo, a psicóloga trata de assuntos que só lhe dizem respeito, a professora de Biologia trata da morfologia, a enfermeira trata dos métodos contracetivos, o padre da escola só trabalha com o contexto moral [...]. Ou seja, tem que haver cumplicidade entre a equipa, para que todos possam aprender com os outros e possam tentar em conjunto resolver o problema em questão. Pois muitas cabeças pensam muito melhor do que uma, mas de uma forma objetiva, rápida e eficaz. Porque os problemas, não se compadecem com o tempo! [...] É bom que eles percebam também que existe absoluta e total confidencialidade. Eimportante integrar nessas equipas os próprios alunos para poderem partilhar experiência e ajudar-nos a compreender a forma como pensam os colegas e a colaborarem na partilha de experiências que possuem em relação à vida dos adolescentes e dos seus problemas reais. [...] Depois, ao longo do projeto em equipa, verificar que algumas apostas não estão a resultar e tentar arranjar outras para atingir os objetivos do Gabinete. Ao fim e ao cabo era ajustar o Gabinete à comunidade que temos, mas isso é um trabalho inacabado, porque a comunidade vai mudando ano a ano e, portanto terá sempre que haver alterações de estratégias para atingir os mesmos ou outros objetivos que eventualmente possam surgir (PB6).

\section{Discussão dos Resultados e Conclusões}

De acordo com a maioria das entrevistadas, o papel da Biologia do ensino secundário assume um lugar privilegiado na educação sexual por: i) permitir a aquisição de conhecimentos na dimensão biológica e preventiva da sexualidade; ii) levar ao desenvolvimento de competências pessoais e sociais; iii) existir um número significativo de alunos/as desinformados/as em relação às medidas preventivas.Estes são também os pressupostos em que se baseiam vários documentos legais que regulamentam a educação em sexualidade em Portugal (PORTUGAL, 2005; LISBOA, 2006, 2005, 2004, 2003, 2001a, 2001b, 2001c, 2000; GRUPO DE TRABALHO DE EDUCAÇÃO SEXUAL, 2007b), os programas nacionais de Ciências Naturais (LISBOA, 2001a) e de Biologia e Geologia $10^{\circ}$ e $11^{\circ}$ ano (LISBOA, 2001b) e de $11^{\circ}$ e 
$12^{\circ}$ ano (LISBOA, 2001c) e vários investigadores (CARDOSO, 2008; CARIDADE, 2008; SILVA, 2006; VILAÇA, 2006; ZAPIAIN, 2003).

Os desafios enfrentados na implementação da educação em sexualidade, apresentados pela maioria das inquiridas foram: i) a real efetivação da educação sexual de forma transversal e interdisciplinar; ii) o estreitamento de laços de amizade entre professor/a e alunos/as; iii) o/a professor/a criar condições para ajudar na construção do projeto de vida dos/as jovens. Estes resultados são concordantes com os mencionados pelos estudos de Cardoso (2008), Costa, A. (2006), Costa, R. (1998), Marques (1999); Lisboa (2005), Grupo de Trabalho de Educação Sexual (2005, 2007a, 2007b) e Vilaça (2006, 2007, 2008).

As barreiras encontradas pela maioria das professoras da amostra em estudo na implementação da educação em sexualidade no ensino secundário foram de três níveis: i) ausência de perfil ideal na maioria dos/as professores/as; ii) identificar os temas a desenvolver e reconhecer o momento de parar, em função da turma presente; iii) desfazer os mitos sexuais e conceções alternativas que persistem ao longo das gerações, tal como já tinham sido referidas nos estudos de Cardoso (2008), Costa (2006), Saavedra et al. (2007), Silva (2006) e Vilaça (2006).

A maioria das entrevistadas encararamo papel do GAA como uma estrutura de suporte na educação em sexualidade no Ensino Secundário. As razões apontadas para isso foram apoiar na construção de um projeto de vida saudável dos/as jovens, através do aconselhamento individual e/ou encaminhamento do/a aluno/a para outras instituições caso a escola não consiga dar resposta, o que está de acordo com a Lei 120/99 (PORTUGAL, 1999), o artigo $2^{\circ}$ da Lei 60/2009 (PORTUGAL, 2009) e o defendido pelas estruturas educativas, como o Lisboa (2001a, 2001b), Grupo de Trabalho de Educação Sexual (2005, 2007a, 2007b), e por vários investigadores (CARIDADE, 2008; COSTA, A., 2006; VILAÇA, 2006).

A desvalorização do GAA, defendida por uma minoria na amostra em estudo, esteve associada a três razões: a dificuldade do/a aluno/a em desabafar os problemas com alguém desconhecido e o receio de falta de sigilo em relação aos pais. Por parte do GAA, algumas destas condições estão previstas na Lei nº0/2009, artigo $7^{\circ}$, alínea 1 e artigo $8^{\circ}$ alíneas 4 e 5 (PORTUGAL, 2009). Estes resultados são semelhantes aos encontrados noutros estudos (LÓPEZ; FUERTES, 1999; WEISSMANN, 2005; SAMPAIO, 1994; MARINIS; COLMAN, 1995; VILAÇA, 2006; FONSECA, 2005). 
A maioria dos inquiridos identificou como barreiras para o bom funcionamento do GAA a falta de infraestruturas, logística, recursos humanos e materiais e cobertura horária para o atendimento. Estes resultados estão de acordo com os obtidos por outros investigadores em Portugal (CARVALHO; PATANÉ, 2008; FIDALGO, 2008; MANDIM, 2007; VILAÇA, 2006; VILAR, 2000).

\title{
THE PERCEPTIONS OF TEACHERS OF SECONDARY EDUCATION IN PORTUGAL REGARDING THE ROLE OFTHE BIOLOGYAND THE STUDENT SUPPORT OFFICE IN SEXUALITY EDUCATION
}

\begin{abstract}
Sexuality education (SE) in Portugal, which is an area of personal and social education, requires the adoption of an open and flexible curriculum with active student participation. For this reason, SE has been integrated into the school curriculum particularly in the Biology subject and in the Student Support Office (SSO). In this sense, a research on Portuguese schools which among other objectives, aimed to characterize the conceptions of teachers of the SSO and theBiology teachersof Secondary Education regarding the role of Biology and the SSO in youth SE and to describe how they conceive the SSO as a supporting structure in SE, was carried out. A qualitative, exploratory and descriptive methodology was used and data collection was done through semi-structured interviews applied to SSO teachers $(n=6)$ and Biology teachers $(n=6)$. Most of the respondents attributed an important role to SE in secondary school to the subject of Biology and the SSO, and understood SE as an interdisciplinary and cross-sectional area whichhelps youths to build a healthy living project. In their perspective, the Biology program allows for the acquisition of the biological understanding of sexuality, hence the importance of its relationship with the SSO. The SSO was viewed as a support structure to SE, because it was seen as collaborating in the projects of SE and as a social service, where the teacher acts as a coach and, when necessary, guides students to other institutions. These results have implications for teacher training, the links between the disciplinary curricular areas and the SSO, and the (re) structuring of the SSO in light of the legal norms.
\end{abstract}

KEYWORDS: Sexuality Education. Biology subject. Student Support Office. Teachers. Portugal.

\section{REFERÊNCIAS}

CARDOSO, S. Projecto VESPAH: alicerce para dias saudáveis. In: BONITO, J. (Ed.). Educação para a Saúde no Século XXI: teoria, modelos e práticas. Évora: Universidade de Évora; CIEP, 2008. p.603-605.

CARIDADE, C. O Papel da escola e da Educação em Ciências na educação sexual dos adolescentes: concepções de professores de Ciências da Natureza e de encarregados de educação da Escola E.B. 2 e 3 de Cabeceiras de Bastos. 2008. 180f. Dissertação (Mestrado em Educação) - Instituto de Educação, Universidade do Minho, Braga, PO, 2008. 
CARVALHO, C.; PATANÉ, R. Gabinete de apoio ao aluno: experiências, intervenções e projectos. In: BONITO, J. (Ed.). Educação para a Saúde no Século XXI: teoria, modelos e práticas. Évora: Universidade de Évora; CIEP, 2008. p.529-534.

COSTA, A. (2006). A educação sexual numa perspectiva de educação para a saúde: um estudo exploratório na Escola Secundária Pluricurricular de Santa Maria Maior de Viana do Castelo. 2006. 194f. Dissertação (Mestrado em Educação) - Instituto de Educação, Universidade do Minho, Braga, PO, 2006.

COSTA, R. A inter e a transdisciplinaridade em educação sexual. Sexualidade e Planeamento Familiar, Lisboa, n.17/18, p.15-17, jan./jun. 1998. 2ª série.

FIDALGO, A. Criação e dinamização de um gabinete de saúde na escola. In: BONITO, J. (Ed.). Educação para a Saúde no Século XXI: teoria, modelos e práticas. Évora: Universidade de Évora; CIEP, 2008. p.455-473.

FONSECA, H. Compreender os adolescentes, um desafio para pais e educadores. Lisboa: Editorial Presença, 2005.

GRUPO DE TRABALHO DE EDUCAÇÃO SEXUAL [GTES]. Educação para a saúde: Relatório final. Lisboa: Editorial Ministério da Educação, 2007a.

Relatório de progresso do Grupo de Trabalho de Educação Sexual. Lisboa: Editorial Ministério da Educação, 2007b.

Relatório preliminar do Grupo de Trabalho de Educação Sexual. Lisboa: Editorial Ministério da Educação, 2005.

LÓPEZ, F.; FUERTES, K. Para compreender a sexualidade. Lisboa: APF, 1999.

MANDIM, J. As dinâmicas para a promoção da saúde numa escola do Ensino Básico do Porto: um estudo de caso. 2007. 167f. Dissertação (Mestrado em Relações Interculturais) - Instituto Coordenador de Investigação, Universidade Aberta, 2007.

MARINIS, D.; COLMAN, O. Educación sexual orientaciones didácticas para la Educación Secundaria Obligatoria. Madrid: Aprendizaje Visor, 1995.

MARQUES, A. M. Orientações técnicas sobre educação sexual em meio escolar: contributo das equipas do projecto. Lisboa: PES, APF, Direcção Geral da Saúde, 1999.

LISBOA. Ministério da Educação. Orientações para a Área de Projecto dos Cursos Científicos-Humanísticos e para os Projectos Tecnológicos dos Cursos Tecnológicos: $12^{\circ}$ ano. Lisboa: Ministério da Educação, 2006.

LISBOA. Ministério da Educação. Educação sexual em meio escolar: tratamento estatístico dos dados de inquérito aplicado em 2003. Lisboa: Ministério da Educação, 2005.

LISBOA. Ministério da Educação. Programa de Biologia $12^{\circ}$ ano Curso CientíficoHumanístico de Ciências e Tecnologias. Lisboa: Ministério da Educação, 2004. 
LISBOA. Ministério da Educação. Reforma do Ensino Secundário: documento orientador de revisão curricular Ensino Secundário. Lisboa: Ministério da Educação, 2003.

LISBOA. Ministério da Educação. Currículo nacional do Ensino Básico: competências essenciais. Lisboa: Ministério da Educação, 2001a.

LISBOA. Ministério da Educação. Orientações curriculares do Ensino Básico: 3. ${ }^{\circ}$ ciclo: ciências físicas e naturais. Lisboa: Ministério da Educação, 2001b.

LISBOA. Ministério da Educação. Programa de Biologia e Geologia $10^{\circ}$ e $1^{\circ}$ ano Curso Científico-Humanístico de Ciências e Tecnologias. Lisboa: Ministério da Educação, 2001c.

LISBOA. Ministério da Educação, Ministério da Saúde, Associação para o Planeamento Familiar. Educação sexual em meio escolar: linhas orientadoras. Lisboa: Editorial do Ministério da Educação, 2000.

PORTUGAL. Lei no 60/2009, de 6 de agosto de 2009. Estabelece o regime de aplicação da educação sexual em meio escolar. Diário da República, Lisboa, 6 ago. 2009. Disponível em: <http://dre.pt/pdf1s/2009/08/15100/0509705098.pdf>. Acesso em: 2 jan. 2010.

PORTUGAL. Despacho $\mathrm{n}^{\circ} 25$ 995/2005, de 28 de novembro de 2005. Diário da República, Lisboa, 28 nov. 2005. Disponível em: <http://legislacao.minedu.pt/np4/np3content/?newsId=1184\&fileName=despacho_25995_2005.pdf >. Acesso em: 2 jan. 2010.

PORTUGAL. Lei no 120/99, de 11 de agosto de 1999. Reforça as garantias do direito à saúde reprodutiva. Diário da República, Lisboa, 11 ago. 1999. Disponível em: <http://www.apf.pt/cms/files/conteudos/file/Anexos\%20EDS/lei\%20120_99_SSR.pdf>. Acesso em: 2 jan. 2010.

SAAVEDRA, L. et al. Género, cultura e sexualidade em jovens portuguesas e portugueses: um programa de educação sexual. Braga: Universidade do Minho, 2007. Disponível em <http://repositorium.sdum.uminho.pt/handle/1822/7278>. Acesso em: 2 jan. 2010.

SAMPAIO, D. Inventem-se novos pais. 4.ed. Lisboa: Editorial Caminho, 1994.

SILVA, I. Educação para os valores: estudo com futuros professores e alunos do $9^{\circ}$ ano de escolaridade. 2006. 453f. Dissertação (Mestrado em Educação) - Instituto de Educação, Universidade do Minho, Braga, PO, 2006.

VILAÇA, M. Acção e competências de acção em educação sexual: uma investigação com professores e alunos do $3^{\circ}$ ciclo do ensino básico e do ensino secundário. 2006. 803f. Tese (Doutorado em Educação) - Instituto de Educação, Universidade do Minho, Braga, PO, 2006. 
Eficácia do paradigma democrático de educação para a saúde no desenvolvimento da acção e competência de acção dos adolescentes em educação sexual. In: CONGRESO INTERNACIONAL GALEGO-PORTUGUÉS DE PSICOPEDAGOXÍA, 9., 2007, Corunha. Anais... Corunha: Universidade da Coruña, Revista Galego-Portuguesa de Psicoxia e Educación, 2007. p.971-982.

Projecto de educação sexual orientado para a acção e participação: efeitos nas escolas, professores, pais e alunos. In: CONGRESSO INTERNACIONAL DE SAÚDE, CULTURA E SOCIEDADE, 3., 2008, Bragança. Anais... Bragança: Associação para a Investigação e Desenvolvimento Sócio-Cultural, 2008. p.128-159.

VILAR, D. As posições recentes de Daniel Sampaio sobre a educação sexual nas escolas. Lisboa: APF, 2000.

WEISSMANN. Adolescencia. Revista Iberoamericana de Educación, Madrid, n.35/36, 2005. Disponível em:

<http://www.rieoei.org/deloslectores/898Weissmann.PDF>. Acesso em: 2 jan. 2010.

ZAPIAN, J. Educação afectivo-sexual na escola. Revista Sexualidade \& Planeamento Familiar, n.36, p.33-38, 2003. 